\title{
Grupo de estudos na formação inicial de professores de matemática
}

DOI 10.26512/Ic.v25i0.23199

Luciano Feliciano de Lima

Universidade Estadual de Goiás

\section{Resumo}

O presente trabalho tem por objetivo refletir sobre as contribuições do grupo de estudos Síndrome do Delta (SD) para a formação inicial de professores de matemática. Por meio desse grupo, busca-se promover uma articulação entre o conhecimento pedagógico e o exercício da docência, relacionando a teoria e a prática em encontros semanais de quatro horas de duração. Para isso, houve uma aproximação com duas escolas públicas da Cidade de Goiás a fim de oferecer aos licenciandos participantes do SD uma formação mais próxima do contexto real da escola, do ensino e da aprendizagem da matemática no ensino médio. Durante o ano de 2017, o trabalho versou sobre tarefas matemáticas para o ensino e a aprendizagem da função polinomial do primeiro grau. Sendo que, as atividades planejadas foram realizadas nas escolas e, posteriormente, discutidas com os professores em formação inicial, com os professores das escolas e com o professor coordenador. Além disso, contribuíram para a produção de artigos e relatos de experiência pessoal que foram apresentados em eventos científicos e compõem o material aqui discutido. Desse modo, a participação nessa ação contribuiu para que os licenciandos: entendessem a importância do domínio do conteúdo para o ensino de matemática, a partir das interações, em sala de aula, com alunos do ensino médio; percebessem a complexidade do processo de ensino e de aprendizagem por meio de observações na ficha avaliativa e no caderno de campo e de reflexões no grupo de estudos; assumissem uma postura investigativa, fundamentando a prática pedagógica na teoria estudada; e socializassem as experiências através da participação, com apresentação de trabalhos, em eventos científicos.

Palavras-chave: Educação Matemática. Formação de Professores. Grupo de estudos Síndrome do Delta. 


\section{Abstract}

The present work aims to reflect about the contributions of the study group called Síndrome do Delta (SD) to the mathematics teachers' training. Through this study group, we seek to promote an articulation between pedagogical knowledge and teaching practice, discussing the relation between theory and practice in weekly meetings. To do this, there was an approximation with two public schools in Goiás town, Brazil, in order to offer to the SD participants an academic training closer to the real context of the school and the teaching and the learning of mathematics in high school. During the year of 2017 the work was about mathematical tasks for teaching and learning of polynomial function of the first degree. The planned mathematical tasks were carried out in schools and later were discussed with the teachers in initial training, the teachers of the schools and with the coordinating teacher. They contributed to the production of articles and experience reports that were presented at scientific events. This production composes the material discussed here considering the literature studied in SD. The participation in this action contributed to the fact that the graduating students: understood the importance of the mastery of the content for the teaching of mathematics, from the interactions in classroom with high school students; perceived the complexity of the teaching and learning process by using observations in the evaluative form and in the field notepad and reflections with the study group; assuming an investigative posture, basing the pedagogical practice through the studied theory; and to socialize the experiences through the participation, with presentation of works in scientific events.

Keywords: Mathematical Education. Teacher training. Group of studies Síndrome do Delta. 


\section{Resumen}

El presente trabajo tiene por objetivo reflexionar sobre las contribuciones del grupo de estudios Síndrome do Delta (SD) para la formación inicial de profesores de matemáticas. Por medio de ese grupo se busca promover una articulación entre el conocimiento pedagógico con el ejercicio de la docencia, relacionando teoría y práctica en encuentros semanales de cuatro horas de duración. Para ello, hubo una aproximación con dos escuelas públicas de la Ciudad de Goiás a fin de ofrecer a los licenciantes participantes del SD una formación más cercana al contexto real de la escuela y de la enseñanza y aprendizaje de las matemáticas en la enseñanza media. Durante el año 2017 el trabajo versó sobre tareas matemáticas para la enseñanza y el aprendizaje de la función polinomial del primer grado. Las tareas matemáticas planificadas se realizaron en las escuelas y posteriormente se discutieron con los profesores en formación inicial, los profesores de las escuelas y el profesor coordinador. Ellas contribuyeron a la producción de artículos y relatos de experiencia que se presentaron en eventos científicos. Esta producción compone el material aquí discutido a la luz de la literatura estudiada en el SD. La participación en esta acción contribuyó para que los licenciandos: entendieran la importancia del dominio del contenido para la enseñanza de matemáticas, a partir de las interacciones en el aula con alumnos de la enseñanza media; se percibían la complejidad del proceso de enseñanza y de aprendizaje por medio de observaciones en la ficha evaluativa $y$ en cuaderno de campo y de reflexiones en el grupo de estudios; asumir una postura investigativa, fundamentando la práctica pedagógica por medio de la teoría estudiada; y socializar las experiencias por medio de la participación, con presentación de trabajos, en eventos científicos.

Palabras clave: Educación Matemática. Formación de profesores. Grupo de estudio Síndrome del Delta. 


\section{Resumé}

Cette presente étude a pour objectif de réflechir aux contribuitions du groupe d'étude Síndrome do Delta (SD) à la formation initiale dês enseignants de mathématiques. À travers ce groupe, nous cherchons à promouvoir une articulation entre La connaissance pédagogique et l'exercice d'enseignement, em associant, théorie et pratique dans lês réunions hebdomadaires d'une durée de quatre heures chacune. Pour ce faire, il y avait un raprochement avec deux écoles publiques de laville de Goiás afin d'offrir aux licencies participants au SD une formation plus proche Du contexte réel de l'école et de l'ensignement et de l'aprentissage dês mathématiques au lycée. Au cours de l'année 2017, Le travail a consisté sur les tâches mathématiques pour enseigner et apprendre la function polynomial du premier degré. Les tâches mathématiques prévues ont été effectuées dans les écoles et ont ensuite été discutées avec les enseignants de la formation initiale, les enseignants des écoles et l'enseignant coordinateur. Elles ont contribué à la production d'articles et de rapports d'expériences que ont été présenté dans des événements scientifiques. Cette production compose le matériel discuté ici à la lumière de la littérature étudiée au SD. La participation à cette action a contribué aux licenciés: qu'ilscomprissent l'importance de la maîtrise du contenu pour l'enseignement des mathématiques, à partir des interactions en classe avec les lycéens; qu'ils perçussent la complexité du processus d'enseignement et d'apprentissage au moyen d'observations dans la fiche d'évaluation et dans le cahier de terrain et de réflexions dans le groupe d'étude;qu'ils assumassent une posture d'investigation, en fondant la pratique de l'enseignement par la théorie étudiée; et qu'ils socialisassent les expériences à travers la participation, avec la présentation des articles, à des événements scientifiques.

Mots-clés: Education mathématique. Formation des enseignants. Groupe d'études Síndrome do Delta.

\section{Introdução}

Este trabalho trata da formação inicial de professores de matemática buscando, por meio do grupo de estudos Síndrome do Delta (SD), promover a articulação entre o conhecimento pedagógico e o exercício da docência, relacionando a teoria com a prática. Para isso, busco uma aproximação com duas escolas públicas da Cidade de Goiás a fim de oferecer, aos licenciandos participantes do grupo, uma formação mais próxima do contexto real da escola, do ensino e da aprendizagem da matemática no ensino médio.

Aproximar a universidade da escola é um fator importante na formação inicial de 
professores. Essa ideia é defendida por pesquisadores como, por exemplo, Pimenta (2007), Gatti, Barretto e André (2011). Esses autores consideram que as normatizações para a formação de professores da educação básica não estão favorecendo essa aproximação, o que fragiliza a relação entre o conhecimento pedagógico e a prática docente. Para Gatti e Barretto (2009), a escola é um elemento, praticamente, ausente em ementas de disciplinas de cursos de Pedagogia, por exemplo. Nesse sentido, podemos dizer que em cursos de formação de professores de matemática isso não é diferente. Como consequência, ocorre uma formação mais abstrata e pouco integrada ao contexto e à realidade da escola em que o profissional irá atuar.

Entendo que o estabelecimento de um canal de comunicação com a escola pública é um grande desafio aos cursos de formação de professores. Contudo, é importante buscar meios para uma aproximação entre os profissionais da educação básica, licenciandose professores universitários com a finalidade de "romper com um modo individualizado de conduzir o processo de formação de professores" (Ghedin, Oliveira \& Almeida, 2015, p. 41).

Uma possibilidade pode ser a elaboração de um projeto de pesquisa no qual os professores da escola, os futuros professores e os professores universitários tivessem interesses compartilhados. As pesquisadoras Andrade e Aparício (2016, p. 72) consideram que uma "experiência com as situações reais das escolas - mediadas pela postura problematizadora e investigativa - é fundamental na formação dos futuros professores".

É sobre essa ação investigativa, desenvolvida pelo grupo de estudos SD, que abordo no presente artigo. O objetivo é refletir sobre a contribuição de grupos de estudos para o desenvolvimento profissional de professores de matemática. Para isso, tratarei da formação do Síndrome do Delta, assim como exporei minha concepção de grupo de estudos. Na sequência, buscarei refletir sobre o desenvolvimento dos licenciandos por meio de diálogo entre os textos produzidos por eles e a literatura sobre alternativas para o ensino e a aprendizagem da matemática. Com isso, busco estabelecer contribuições para o desenvolvimento profissional dos licenciandos participantes do SD.

\section{Grupo de estudos como estratégia para repensar os papéis de professor e aluno na aula de matemática}

No ano de 2017, tive a oportunidade de coordenar/orientar os bolsistas do PIBID e do Pró-Licenciatura o que me auxiliou a consolidar o grupo de estudos Síndrome do Delta. Os programas PIBID e Pró-licenciatura potencializaram, por meio de bolsas aos professores da educação básica em formação inicial e da universidade, 
maior possibilidade de trabalho colaborativo. Com isso, desenvolvemos uma ação, privilegiando a pesquisa, para contribuir com um contexto de formação que possibilitasse, por intermédio do grupo de estudos, uma construção coletiva de saberes. Nesse direcionamento, foi sugerido aos bolsistas, professores em formação inicial, em acordo com os professores das escolas, a elaboração de tarefas de matemática baseadas em uma perspectiva dialógica e investigativa para o ensino de funções.

Entendo, como propõe Fiorentini (2012, p. 7), essa maneira de trabalho em conjunto como uma aprendizagem para lidar com os desafios da escola contemporânea. Nesse sentido buscamos negociar e construir "outras práticas de ensinar e aprender matemática que sejam potencialmente formativas aos alunos, despertando neles o desejo de aprender e de se apropriar dos conhecimentos fundamentais à sua inserção social e cultural".

Por esse motivo, a ação assumiu uma estratégia de formação incentivando e possibilitando uma construção coletiva de saberes, valorizando uma reflexão para a ação, com os planejamentos das aulas; uma reflexão na ação, durante a realização das aulas - a partir da produção de observações para composição de caderno de campo; e uma reflexão sobre a ação - desenvolvida para a produção de trabalhos socializados em eventos científicos. Esse trabalho de pesquisa, potencializado pelo SD, buscou "alternativas comprometidas com a prática social, que revela escolha, opção de vida, espaço de construção, de troca de experiências, de desejo e de devir" (Ghedin, Oliveira \& Almeida, p. 53, 2015).

O SD se orientou pela pesquisa porque visávamos contribuir com a formação de professores como sujeitos produtores de conhecimento, para além de desempenhar uma função exclusivamente técnica de reprodutor de teorias e ideologias impostas ao professor e à sociedade. Professores em formação para a construção de escolas como "poderosos cenários de aprendizagem, onde os alunos investigam, compartilham, aplicam e refletem" (Pérez Gómez, 2015, p. 29).

Quando o professor se torna um sujeito produtor de seu próprio conhecimento ele também se torna construtor de seu modo de ser, de fazer. Esse entendimento permeou o processo formativo do grupo, promovendo a participação, o compartilhamento de ideias, a defesa de opiniões. Para, além disso, entendo, com André (2016), que o grupo possibilitou a aprendizagem do convívio social. Ao admitirmos o conhecimento como produção social, num processo de compartilhamento de experiências, está implícita a necessidade de que um:

Aprendizado na pesquisa inclui aprender a ouvir o outro, a trocar ideias, a compartilhar. No grupo, posso ampliar meu ponto de vista, conhecer perspectivas diferentes da minha, comparar, estabelecer relações, discordar, concordar, acolher críticas e sugestões que ajudem a melhorar meu trabalho. O processo de formação tem que oferecer oportunidades para que isso aconteça (André, 2016, p. 24). 
Levando em conta o exposto por André (2016), a organização do SD privilegiou características, tais como as defendidas por Fiorentini (2004), em que os participantes: a) compartilham significados acerca do que estão fazendo e aprendendo e o que isso significa para suas vidas e prática profissional; b) têm oportunidade de produzir e sistematizar conhecimentos através de estudos investigativos sobre a prática de cada um, resultando, desse processo, a produção de textos escritos, os quais possam ser publicados e socializados.

Entendo o SD como uma excelente maneira para se aprender a fazer pesquisa, afinal, conforme Murphy e Lick (2005), em um grupo de estudos todos podem compartilhar experiências e ideias. Tendo um objetivo em comum, é possível alcançar os resultados almejados por todos. O decorrer desse trabalho torna os participantes mais harmoniosos, afinal eles passam a confiar mais uns nos outros e aprendem a trabalhar em conjunto.

Gimenes e Penteado (2008) acrescentam que, o trabalho com grupo de estudos, pode: i) promover momentos para o aprofundamento da matemática e suas aplicações por meio da investigação de ideias matemáticas; ii) orientar o desenvolvimento de trabalhos de forma individual, em um número reduzido ou com todos os integrantes.

A organização de comunidades de aprendizagem, de acordo com Kenski (2007), ou de grupos de estudos, como propostos por Ferreira (2003), Fiorentini (2004) e Murphy e Lick (2005) pode ser uma estratégia para a formação de professores com reflexões teóricas e práticas.

A participação em um grupo de estudos, como o Síndrome do Delta, permite reflexões sobre a prática educativa com discussões sobre frustrações, expectativas, dificuldades, alegrias e compartilhamentos de experiências. Os membros apoiam-se mutuamente oferecendo, não raro, sugestões para superação dos desafios enfrentados.

Especificamente em relação ao conteúdo matemático, houve a opção, após diálogo com os professores das escolas, em se planejar atividades envolvendo a função polinomial do primeiro grau e em refletir sobre as potencialidades da abordagem dialógica e investigativa no processo de ensino e aprendizagem desse conteúdo. Os licenciandos organizaram-se em quatro grupos para desenvolverem seus trabalhos a partir das temáticas: i) História da Matemática; ii) O uso de jogos no ensino de matemática; iii) A utilização de TIC na aula de matemática e iv) Avaliação nas aulas de matemática.

É importante ressaltar que no Síndrome do Delta o trabalho é sempre desenvolvido coletivamente, ou seja, todas as atividades realizadas com os alunos do ensino médio, de duas escolas da rede pública da Cidade de Goiás, foram feitas em conjunto e contam com a colaboração de todos os integrantes do SD.

A parceria com os professores da escola foi essencial para a realização desse trabalho, pois, entendo que "o professor aprende com o outro - os alunos, os pares na escola, os colegas de grupo, os professores acadêmicos e de que o grupo é potencializador 
dessas aprendizagens, principalmente se ele adquire uma dimensão colaborativa" (Nacarato, 2011, p. 33). Estou compreendendo a dimensão colaborativa como uma prática comum, de uma reunião de pessoas, com a intenção de "estudar, refletir, analisar e compartilhar o vivido nos contextos escolares - seja como estudante, ou como profissional" (Nacarato, 2011, p. 44).

O SD buscou se configurar como um grupo colaborativo à medida que os envolvidos estavam interessados em crescer profissionalmente. Conforme Ferreira e Miorim (2011), os participantes estavam criando e compartilhando significados sobre o que faziam, sobre suas vidas e práticas profissionais. Sentiam-se confortáveis para expressar ideias, ouvir críticas e mudar de perspectiva.

O que motivou o SD foi pensar em alternativas para um modelo de ensino exclusivamente transmissor de conteúdos e informações a serem reproduzidas mecanicamente pelos alunos. Buscou-se, por meio desse trabalho, pensar em superar um modelo de ensino em que o professor somente aponta os erros dos alunos sem uma preocupação em analisar e refletir sobre o que está errado.

Para refletirmos sobre isto, realizamos leituras da área de educação matemática e de educação. Textos como, por exemplo, André (2016), Pérez Gómez (2015), Alarcão (2007), Imbernón (2006), nos auxiliaram nessa reflexão ao defenderem a ideia de que vivemos, atualmente, em uma sociedade conectada pela informação e, por isso, há muitas formas de obtê-la para além da escola. Para esses autores, um modelo pedagógico, exclusivamente centrado na transmissão de informações e de técnicas, em que o professor espera que o aluno reproduza, integralmente, o que fora transmitido, está cada vez mais obsoleto. Essas reflexões contribuíram com o desenvolvimento de ações que foram realizadas com alunos do ensino médio e refletidas no SD.

No Síndrome do Delta adotamos como estratégia, para a formação docente, a produção de tarefas matemáticas numa perspectiva dialógica e investigativa. Os planejamentos das tarefas, sua realização em sala de aula com alunos da educação básica e a reflexão sobre as mesmas constituíram material para a produção de artigos e relatos de experiência para apresentação em eventos científicos. Esses trabalhos serão utilizados no presente texto para analisarmos possíveis contribuições do grupo de estudos para a formação de professores de matemática.

Para a realização da ação com os alunos do ensino médio foram constituídas as seguintes metas: a) estabelecimento de um diálogo com a escola pública; b) viabilização de experiências com situações reais da escola aos licenciandos e; c) promoção de uma postura problematizadora e investigativa em seus participantes. Nesse sentido, buscou-se discutir sobre possibilidades de ensino, com professores da educação básica, a fim de planejar tarefas matemáticas para a sala de aula que, depois de realizadas com os alunos, foram refletidas pelos participantes do SD. As reflexões sobre essas atividades permitiram o aperfeiçoamento das mesmas e potencializaram as discussões sobre perspectivas teórico-metodológicas realizadas com os professores em formação. 
Durante o ano de 2017, os participantes do SD desenvolveram tarefas matemáticas sobre função polinomial do primeiro grau. Esse trabalho resultou, para além das reflexões no grupo, em trabalhos escritos apresentados como comunicação científica e como relatos de experiência em eventos acadêmicos de Educação Matemática. Nesses trabalhos os participantes refletiram sobre abordagens pedagógicas para além "da mera transmissão (ensino teórico e aulas expositivas) de explicações e de teorias e no adestramento (ensino prático com exercícios repetitivos) em técnicas e habilidades" (D'Ambrósio, 2016, p. 141).

Para discutir sobre outras abordagens pedagógicas os participantes apoiaram-se em autores como, por exemplo, D’Ambrósio (2016), André (2016), Pérez Gómez (2015), Freire (2011), Alrø e Skovsmose (2010), Skovsmose (2007), Alarcão (2007) e Imbernón (2006). Os trabalhos desses pesquisadores proporcionaram discussões sobre relações entre a escola e a sociedade. Contribuindo para uma percepção, pelos componentes do grupo, da educação para além de um conjunto de técnicas visando à manutenção de uma sociedade injusta e desigual. Compreendendo que, "na sua melhor forma a Educação é muito mais do que técnicas, a Educação é uma forma de entender o mundo com a finalidade de transformá-lo" (Freire, 2016, p. 101).

Entender o mundo por meio da matemática, para nós do Síndrome do Delta, implica em um ensino e aprendizagem que faça sentido aos alunos. A mera reprodução de técnicas contribui muito pouco com a apropriação do conhecimento matemático para a compreensão do mundo e sua transformação. Por esse motivo, os membros do grupo pensaram em possibilidades pedagógicas para um ensino no qual os alunos sejam sujeitos produtores de conhecimentos. Cabe dizer que o ambiente do SD teve a intenção de promover, aos licenciandos, "um clima propício para a participação, para a emergência de sujeitos questionadores, críticos, criativos, que ao viverem essa experiência poderão posteriormente replicá-la com seus alunos" (André, 2016, p. 22).

O clima estabelecido no grupo de estudos buscou potencializar a superação da resistência às mudanças. A fim de que, em sua prática pedagógica futura, em escolas da educação básica, os licenciandos participantes do SD, atuem em suas aulas a partir dos referenciais teóricos refletidos na e sobre a prática durante a formação inicial. A esperança é que não se rendam "à cultura da escola, (...) abandonando os referenciais da ciência que os formou" (Ghedin, Oliveira \& Almeida, 2015, p. 36).

Cultura escolar derivada, e/ou reforçada, por uma resistência fortemente fundada em "tradições e modelos pedagógicos que, se alguma vez tiveram sentido, [...] certamente hoje já não tem" (Pérez Gómez, 2015, p. 11). Por isso, durante a formação inicial de professores, é imprescindível refletir sobre alternativas pedagógicas em "que os alunos abandonem os papéis de meros receptores e os professores sejam muito mais do que simples transmissores de um saber acumulado" (Alarcão, 2007, p. 25).

Dificilmente mudanças na educação básica serão possíveis "sem um novo conceito de profissionalização do professor, que deve romper com inércias e práticas do passado 
assumidas passivamente como elementos intrínsecos à profissão" (Imbernón, 2006, p. 19). Por isso, cabe incentivar os licenciandos a debruçarem-se sobre o trabalho que desenvolvem em suas ações nas escolas da educação básica, visando refletirem sobre o que fazem e como o fazem, que ponderem sobre as potencialidades e as dificuldades do exercício da docência para mudar, quando necessário, com o intuito de obter melhores resultados.

A aprendizagem se dá mediante convívio social, pois "ninguém educa ninguém, ninguém educa a si mesmo, os homens se educam entre si, mediatizados pelo mundo" (Freire, 2011, p. 95). Acrescente-se a isso que "o conhecimento é construído ativamente pelo aprendiz [e] não é passivamente recebido pelo exterior" (Pérez Gómez, 2015, p. 47). Por esses motivos, é importante manter um diálogo com os profissionais da escola para juntos, licenciandos, professores da educação básica e professor universitário, pensarem possibilidades para promover um ensino que faça sentido aos educandos e que estimule a participação deles nas aulas de matemática.

Pensando a formação docente, de acordo com Garcia (1990, p. 26), como um momento para compartilhamentos de:

Experiências de aprendizagem através das quais [se] adquirem ou melhoram os seus conhecimentos, competências e disposições, e que lhes permite intervir profissionalmente no desenvolvimento do seu ensino, do currículo e da escola, com o objetivo de melhorar a qualidade da educação que os alunos recebem.

Entendo o grupo como uma excelente oportunidade para refletir sobre o papel do professor no desenvolvimento de um ambiente estimulante para um trabalho com a matemática. Por isso, discuto, na próxima seção, sobre as reflexões escritas dos licenciandos, participantes do grupo de estudos Síndrome do Delta, que foram socializadas em eventos científicos. A partir delas explicitamos e analisamos alguns excertos desses textos que consideramos relevantes e representativos do processo de formação inicial viabilizado pelo grupo de estudos.

\section{Síndrome do Delta: reflexões sobre aulas de matemática contribuindo com o desenvolvimento profissional}

No Síndrome do Delta ,ocorreram discussões visando o planejamento de tarefas para um ensino que pudesse envolver ativamente os alunos. Nesse sentido, a prática do grupo tem sido refletida à luz da literatura entendendo, por exemplo, como Alarcão (2007, p. 26), que cabe ao aluno "descobrir o prazer de ser uma mente ativa e não meramente receptiva". Nesse sentido ele é considerado como sujeito produtor do próprio conhecimento, cabendo ao professor exercer o papel fundamental de 
"criar, estruturar e dinamizar situações de aprendizagem e estimular a aprendizagem e a autoconfiança nas capacidades individuais [dos alunos] para aprender" (Alarcão, 2007, p. 30).

Para estimular uma aprendizagem ativa nos alunos do ensino médio o grupo se baseou numa concepção de cenários para investigação, como sugerem Alrø e Skovsmose (2010. Esses espaços foram compreendidos como ambientes que demandam maior envolvimento dos alunos na formulação de questões e no planejamento de linhas de investigação de maneira diversificada. Neles são considerados dois elementos básicos para que ocorra o processo investigativo: i) a tarefa matemática não pode ser compulsória, demandando o envolvimento dos participantes; ii) deve ser um processo aberto. Resultados e conclusões não podem ser determinados de antemão. "Os alunos devem ser convidados para um cenário para investigação, a fim de se tornarem condutores e participantes ativos do processo de investigação" (Alrø \& Skovsmose, 2010, p. 59).

Assim, se os licenciandos não tiveram contato com um cenário para investigação durante sua etapa como discentes da educação básica, eles têm essa oportunidade durante a sua formação como professores. Nesse processo, aprendem a estimular os alunos a descobrirem o prazer da descoberta a partir de uma participação ativa durante a aula. Exemplo disso pode ser visto no excerto de um relato de experiência apresentado no VII CIEM (Congresso Internacional de Ensino da Matemática, na ULBRA em Canoas/RS) pelos integrantes do Síndrome do Delta que desenvolveram um trabalho envolvendo jogos com alunos do ensino médio. Eles afirmam: ${ }^{*} E m$ nosso entendimento, numa aula de matemática, quando um aluno comenta que ao darmos uma resposta, para ele resolver um problema, faz perder a graça da atividade, como aconteceu numa aula, é algo que consideramos como positivo. Afinal, isso nos mostra que nosso objetivo, de promover ambientes para os alunos serem participativos, expressarem suas opiniões, argumentarem matematicamente, está sendo alcançado. Isso nos mostra que os alunos estão se sentindo mais seguros em relação às suas capacidades matemáticas e desenvolvendo uma atitude de perseverança na solução de problemas. Para nós, isso significa que os alunos estão começando a entender a importância em se assumirem como sujeitos participativos e críticos em relação ao conhecimento, e por isso mesmo, entendendo-se como produtores de conhecimento*1.

Nesse excerto é possível perceber que estão compreendendo a relevância em considerar seus alunos como sujeitos de conhecimento. Por isso, destacam a importância de o aluno considerar chegar, por conta própria, na resposta para um problema. Percebem que um problema, e a busca por sua solução, devem ser interessantes aos alunos e não ao professor, pois não é mais um problema se se tem um sistema de resposta anteriormente definido dado pelo professor. Estão preocupados

1 O relato de experiência pode ser acessado no endereço: http://www.conferencias.ulbra.br/index.php/ciem/vii/ paper/viewFile/7183/3492. 
com o prazer da descoberta de seus alunos e vão percebendo a importância do professor fazer perguntas e orientar os estudantes a buscarem respostas, no lugar de simplesmente oferecê-las. Vão percebendo a importância de o professor fazer perguntas com a intenção de que os alunos reflitam sobre a atividade proposta.

Nesse processo de fazer perguntas aos alunos, busca, como aconselha Freire (1996), o estabelecimento de um diálogo verdadeiro entre professor e alunos. Para Freire (1996), esse diálogo acontece somente se professor e alunos estiverem, simultaneamente, conversando sobre um objeto inteligível a ambos. E aí reside a preocupação dos licenciandos em fazer perguntas com o intuito de criar, desse modo, um ambiente para a promoção de um espírito crítico no aluno, algo fundamental para que o mesmo possa se tornar um sujeito mais autônomo. Os licenciandos, nesse processo, vão percebendo que o professor assume um papel importante, o de problematizador do conteúdo a ser trabalhado com os alunos. Segundo Freire (2011a) o educador é um inventor e reinventor de caminhos para promover o pensamento crítico dos educandos. Para que os alunos tenham a oportunidade de serem críticos, o professor também precisa refletir criticamente sobre sua ação e é o que estão fazendo os licenciandos em sua participação no Síndrome do Delta, assim como na produção escrita e no compartilhamento com os pares sobre suas perspectivas de ensino e de aprendizagem.

A participação no grupo Síndrome do Delta viabiliza, como destacado no excerto de texto citado anteriormente, aos seus membros perceber a importância de relacionar o conhecimento aprendido na universidade com a prática vivenciada no exercício da docência. Durante as reuniões, a partir das discussões sobre os trabalhos realizados, os licenciandos assumem uma postura investigativa sobre o processo de ensino. Além disso, trabalham colaborativamente compartilhando inquietações, criticando os trabalhos (relatos de experiência e artigos) uns dos outros, dando sugestões para aperfeiçoar aquilo que não consideraram muito bom. Nesse processo, estão refletindo sobre a prática, por meio da teoria, compartilhando conhecimentos, trabalhando colaborativamente, realizando pesquisa e, consequentemente, produzindo conhecimentos. De acordo com Mizukami (2013, p. 27):

A compreensão e a prática da atitude investigativa podem ajudar professores a identificar e a analisar suas aprendizagens ao mesmo tempo em que lhes são oferecidas ferramentas para análise de episódios e situações complexas de sala de aula e de vida escolar.

Cabe dizer que a participação dos professores da escola campo contribui com a produção de um conhecimento sobre a ação de ensinar. Ou seja, a escola não é considerada pelo grupo como um local para aplicações das teorias discutidas na universidade, e sim como mais um espaço para discussões sobre potencialidades da teoria, exposições de pontos de vista e de teorias distintas e de compartilhamentos de experiências com vistas à melhoria da qualidade de ensino da educação pública. 
Refletir para/na/sobre a prática, como sugerem Alarcão (2007) e Imbernón (2006), tem sido adotado nas reuniões do Síndrome do Delta. No grupo, buscamos criar um ambiente de ensino e aprendizagem com estímulo à pergunta e com reflexão crítica sobre a própria pergunta. Ou seja, há um entendimento de que a postura do professor e dos alunos "é dialógica, aberta, curiosa, indagadora e não apassivada, enquanto fala ou enquanto ouve. O que importa é que professor e alunos se assumam epistemologicamente curiosos" (Freire, 1996, p. 95-6). Concorda-se com Freire (2011b) que, nesse processo, o educador exerce a tarefa essencial de ouvir o outro, desafiando-o por meio de questionamentos, para que reflita sobre a temática estudada e sobre as próprias respostas no decorrer da aula.

Por estarem preocupados em ouvirem o outro, durante as aulas, os licenciandos que trabalharam a problemática da avaliação do processo de ensino e aprendizagem discorreram da seguinte forma, em relato de experiência apresentado no VII CIEM: * De acordo com nossas observações nas fichas avaliativas percebemos que diversos alunos não estavam participando das atividades. Pode ser que se sentissem desmotivados, então propusemo-nos a desenvolver atividades mais dinâmicas e que estimulassem os alunos a interagirem entre $\mathrm{si}^{* 2}$.

Nesse excerto, os licenciandos fazem uma autocrítica sobre a própria aula e mostram sua preocupação em rever e refazer os planejamentos das aulas, buscando maior participação dos alunos. Mostram, com isso, entenderem a importância do envolvimento dos alunos na aula, pois, como entendemos no Síndrome do Delta, o engajamento dos alunos contribui para a formação de cidadãos criativos, com capacidade de trabalhar autonomamente e colaborativamente, imbuídos de um espírito crítico. Dificilmente isso ocorreria se os licenciandos, no lugar de pensarem outras tarefas para envolverem os alunos, resumissem suas aulas a monólogos expositivos. Visto que, "o desenvolvimento do espírito crítico faz-se no diálogo, no confronto de ideias e de práticas, na capacidade de se ouvir o outro, mas também de se ouvir a si próprio e se autocriticar" (Alarcão, 2007, p. 32).

Assim, experiências como a do Síndrome do Delta, durante a licenciatura em matemática, auxiliam os professores em formação a perceberem seus alunos, ou futuros alunos, como sujeitos produtores de conhecimento. E, possivelmente, oferecerão ambientes de sala de aula com "um profundo respeito pela identidade cultural dos alunos e das alunas" (Freire, 2014, p. 92). Respeito à linguagem, à cor, ao gênero, à classe social, à orientação sexual e à capacidade intelectual dos alunos. Os futuros professores aprendem no exercício da prática, por meio de suas ações, o respeito ao outro. Consequentemente, pensarão na criação de espaços em que o aluno se sinta acolhido e com liberdade para se posicionar ao expor suas ideias, argumentar possíveis soluções para um problema, questionar o professor e os demais colegas. Nesse movimento, o

2 O relato de experiência pode ser acessado no endereço: http://www.conferencias.ulbra.br/index.php/ciem/vii/ paper/viewFile/7416/4410 
professor em formação vai desenvolvendo a habilidade de estimular a criticidade e a criatividade de seus alunos. Elementos considerados por D'Ambrósio (2016) como metas da educação.

Buscando desenvolver a criatividade e a capacidade de argumentação matemática dos alunos, os licenciandos que desenvolveram tarefas com o Software GeoGebra, em relato de experiência do VII CIEM consideram que: *Por meio da abordagem dialógica e investigativa busca-se viabilizar o trabalho dos alunos, com o software GeoGebra em um ambiente informatizado, para que produzam conhecimento sobre o objeto de estudo, em nosso caso, das funções polinomiais do primeiro e segundo graus. O aluno, em ambientes desse tipo, por exemplo, reflete a respeito dos coeficientes da função polinomial e percebem a relação entre o coeficiente angular, esta função, para produzir o movimento do braço do homem representado no GeoGebra. Nesse sentido, ele está envolvido em seu processo de aprendizagem*3.

Percebe-se uma preocupação dos licenciandos em promover a criatividade dos alunos a partir do uso de um software. Eles estão interessados em que os alunos relacionem o coeficiente angular, da função polinomial do primeiro grau, com um movimento na tarefa de construir algo com o GeoGebra. Pensam na aula de matemática como algo além de uma sequência para transmissão de conteúdo, seguido de exemplo e com uma enorme lista de exercícios para serem resolvidos, porque consideram que aulas assim contribuem muito pouco com "a ideia de criatividade e a importância do desenvolvimento de competências matemáticas que podem ser usadas nas situações de vida cotidiana" (Skovsmose, 2007, p. 36).

Para que os licenciandos participantes do Síndrome do Delta reconheçam a quem serve sua atividade profissional, valorizando mais e mais o ser humano,em um processo de inclusão e de respeito às diferenças, constantemente, são convidados a pensar nessa problemática e a elaborarem tarefas matemáticas nas quais se considera o aluno como sujeito de conhecimento. Para isso, os licenciandos, desde sua formação inicial, vão se assumindo como educadores progressistas visando minimizar, ao máximo, por meio de suas ações, a exclusão escolar, indo além do "ensino de puras técnicas ou de puros conteúdos, deixando intocado o exercício da compreensão crítica da realidade" (Freire, 2013, p. 51). Nesse sentido, os membros do grupo de estudos vão se constituindo, desde o início do curso de licenciatura, professores compromissados em promover aulas para que seus alunos trilhem e produzam caminhos como "seres no mundo, com o mundo, e com os outros, por isso seres de transformação e não de adaptação a ele" (Freire, 2013, p. 37). Esse movimento possibilita refletir sobre a importância de:

Uma educação crítica, desveladora, desocultadora e não ocultadora de verdades. $O$ argumento segundo o qual o puro ensino do conteúdo, o conteúdo depositado no educando, (que, para mim, não é ensino de acordo com a compreensão que de seu

3 O relato de experiência pode ser acessado no endereço: http://www.conferencias.ulbra.br/index.php/ciem/vii/ paper/viewFile/6873/3315 
processo tenho) cedo ou tarde provocará a percepção crítica da realidade não me satisfaz nem convence porque, devendo ser, na perspectiva progressista, o processo de ensinar, um processo crítico em que o ensinante desafia o educando a aprender o objeto ou conteúdo para aprendê-lo em suas relações com outros objetos, ensinar conteúdos implica o exercício da percepção crítica, de sua ou de suas razões de ser. Implica o aguçamento da curiosidade epistemológica do educando que não pode satisfazer-se com a mera descrição do conceito do objeto. Não devo deixar para um amanhã aleatório algo que faz parte agora, enquanto ensino, de minha tarefa de educador progressista: a leitura crítica do mundo ao lado da leitura crítica da palavra (Freire, 2013, p. 101).

É mais provável um professor contribuir com a formação de futuros cidadãos, como sujeitos críticos e participativos, se vivenciou experiências nesse sentido durante a graduação. Esse é um grande desafio a se assumir com os profissionais da escola. Juntos, professores em formação, professores da escola e professores da universidade podem pensar em um ensino, e em uma aprendizagem, que auxilie os alunos a relacionarem os conteúdos aprendidos com a vida, assim como a realizarem um trabalho autônomo e colaborativo. D'Ambrósio (2016) nos alerta sobre a necessidade de superarmos currículos escolares desinteressantes, obsoletos e, em grande medida, inúteis. Considerando que eles distanciam a sala de aula da realidade do mundo quando as experiências, de alunos e de professor, são deixadas de lado tendo como consequência um ensino de caráter artificial e irreal. Para ele, o mundo atual exige "outros conteúdos, naturalmente outras metodologias, para que se atinjam os objetivos maiores de criatividade e cidadania plena" (D’Ambrósio, 2016, p. 39).

Para D’Ambrósio (2016, p. 25), as transformações sociais que implicam em novas "formas de conhecer, novos modelos de ciência, novas relações conhecimentoprofessor-aluno exigem um novo paradigma para a educação". O desenvolvimento desse novo padrão demanda um professor que se perceba responsável pela formação de sujeitos críticos e não somente como mais uma fonte de informação aos alunos, dentre tantas outras. Por esse motivo, os participantes do Síndrome do Delta buscam compreender a educação como "o conjunto de estratégias desenvolvidas pelas sociedades para: a) possibilitar a cada indivíduo atingir seu potencial criativo; b) estimular e facilitar a ação comum, com vistas a viver em sociedade e exercer a cidadania" (D’Ambrósio, 2016, p. 32).

Dessa maneira, os membros do grupo de estudos vão compreendendo outro modelo educacional no qual a aprendizagem é vista como uma ação de construir e reconstruir, como um movimento de superação da curiosidade ingênua (senso comum) que se transforma em curiosidade crítica. As construções e reconstruções, visando à aprendizagem e à produção de um pensamento crítico, são potencializadas pelos ambientes educativos criados pelo professor. Assim, o educador subordina os conteúdos das disciplinas "aos objetivos da educação e não a educação aos objetivos, à transmissão e aos avanços das disciplinas. O estudante deve ser, como indivíduo, o determinante do conhecimento que Ihe é transmitido" (D’Ambrósio, 2016, p. 32). 
Nesse sentido, os licenciandos vão compreendendo, como afirma Mantoan (2015, p. 22), que "aprender implica ser capaz de dar significado a objetos, fatos, fenômenos, à vida". Assim, os membros do Síndrome do Delta, vão (re)significando a aula de matemática como um espaço para o aluno atribuir significados aos conteúdos e aos conceitos estudados, expressando e refletindo, com o professor e com os demais colegas, sobre seu entendimento do assunto trabalhado. E a abordagem investigativa foi adotada pelo grupo como uma abordagem pedagógica nessa direção.

\section{Considerações}

O grupo de estudos Síndrome do Delta foi uma forma de viabilizar uma formação inicial para professores de matemática refletirem sobre a melhoria do ensino de matemática na educação pública. Por isso, o diálogo com a escola e com os professores de matemática, buscando aproximação entre universidade e escola, na intenção de criar possibilidades que entrelacem o conhecimento da academia e o da prática na sala de aula de matemática na educação básica. Mantendo, assim, um diálogo respeitoso e aberto para novas aprendizagens, contribuindo com a formação inicial dos participantes do grupo.

Neste artigo buscamos refletir sobre uma estratégia para a formação de professores de matemática, o grupo de estudos Síndrome do Delta. Para tanto, discutimos com professores da educação básica o desenvolvimento de tarefas matemáticas para o ensino e a aprendizagem da função polinomial do primeiro grau. Os professores de matemática, assim como os demais profissionais da escola, nos receberam muito bem, inclusive, reorganizando os horários para contribuir com o desenvolvimento da ação.

Nesse sentido, o trabalho em conjunto permitiu aos licenciandos uma longa inserção na escola, trazendo para o grupo de estudos materiais que foram discutidos e aperfeiçoados. É importante ressaltar o envolvimento dos licenciandos no planejamento e no desenvolvimento das tarefas com os alunos do ensino médio, bem como, o empenho em trazer elementos para serem refletidos pelo grupo, visando aperfeiçoar o trabalho e compartilhar conhecimentos por meio da produção de comunicações científicas e de relatos de experiências, apresentados em eventos científicos de educação matemática.

O ambiente do SD permitiu a ampliação de pontos de vista a partir de compartilhamentos, discussões e reflexões de textos sobre educação e educação matemática. Somando-se a isso, ao apresentarem e discutirem os planejamentos, refletindo sobre as ações desenvolvidas, ocorreram momentos proveitosos para se pensar o ensino e a aprendizagem da matemática na escola pública. Esse processo de compartilhamento possibilitou o aperfeiçoamento da produção escrita, visto que, 
sempre com muito respeito, os participantes contribuíam com sugestões e críticas sobre os trabalhos uns dos outros.

Somando-se a isso, o grupo contribuiu com reflexões no sentido de como agir em sala de aula, em reuniões com colegas ou com pais de alunos, dentre outras situações. Nesse sentido, o grupo colaborou com o desenvolvimento de habilidades para "ajudar a compreender o que se passa no ambiente de trabalho e a encontrar estratégias para enfrentamento dos desafios que surgem cotidianamente na prática profissional" (André, 2016, p. 24).

Cabe dizer que a participação no grupo de estudos contribuiu para que os licenciandos: entendessem a importância do domínio do conteúdo para o ensino de matemática, a partir das interações, em sala de aula, com alunos do ensino médio; percebessem a complexidade do processo de ensino e de aprendizagem por meio de observações na ficha avaliativa e no caderno de campo e de reflexões no grupo de estudos; assumissem uma postura investigativa, fundamentando a prática pedagógica por meio da teoria estudada no grupo e; socializassem as experiências por meio da participação, com apresentação de trabalhos, em eventos científicos.

O grupo, como dito anteriormente, fundamenta-se numa abordagem dialógica e investigativa para o ensino e a aprendizagem da matemática, valorizando as interações humanas e compreendendo os alunos como sujeitos históricos e sociais, e, por isso mesmo, como sujeitos produtores de conhecimento.

No desenvolvimento das atividades, os licenciandos foram percebendo a dificuldade em fazer perguntas para que os alunos refletissem sobre o problema apresentado e, também, em manter um diálogo no qual alunos e professor tratassem do objeto de estudo - com vistas a entendê-lo e a buscar soluções. Além disso, na sala de aula do ensino médio, os licenciandos ficavam atentos ao trabalho dos alunos, anotando o desempenho deles em uma ficha avaliativa, fazendo observações sobre a potencialidade da tarefa e o desenvolvimento da aula. As anotações serviram de material para discussão durante as reuniões do grupo de estudos.

Desse modo, a participação no grupo possibilitou aos licenciandos o envolvimento em uma proposta de formação docente com vista ao desenvolvimento da capacidade de adaptação à realidade da sala de aula de matemática de escolas públicas. Por fim, ao criarem os materiais didáticos, os participantes perceberam a importância do planejamento das aulas e da busca de uma aprendizagem significativa. 


\section{Referências}

Alarcão, I. (2007). Professores Reflexivos em uma Escola Reflexiva, 5 ed. Coleção Questões da nossa época. São Paulo, Cortez Editora.

Alrø, H., \& Skovsmose, O. (2010). Diálogo e Aprendizagem em Educação Matemática. Coleção Tendências em Educação Matemática. Tradução: Orlando Figueiredo. Belo Horizonte: Autêntica.

Andrade, M. F. R., \& Aparício, A. S. M. (2016). A construção colaborativa de sequências didáticas de gêneros textuais: uma estratégia inovadora de formação docente. In Práticas inovadoras na formação de professores. Marli André (org.) Campinas, SP: Papirus.

André, M. (2016). Formar o professor pesquisador para um novo desenvolvimento profissional In Práticas inovadoras na formação de professores. Marli André (org.) Campinas, SP: Papirus.

D’Ambrósio, U. (2016). Educação para uma sociedade em transição. 3. ed. Revista e ampliada. São Paulo: Editora Livraria da Física.

Ferreira, A. C. (2003). Metacognição e desenvolvimento profissional de professores de matemática: uma experiência de trabalho colaborativo. Tese de Doutorado, Universidade Estadual de Campinas, Campinas.

Fiorentini, D. (2004). Pesquisar práticas colaborativas ou pesquisar colaborativamente? In: BORBA, M. C.; ARAÚJO, J. L. (org.). Pesquisa Qualitativa em Educação Matemática. Belo Horizonte: Autêntica.

Freire, P. (1996). Pedagogia da autonomia: saberes necessários à prática educativa. Coleção Leitura. São Paulo: Paz e Terra.

Freire, P. (2011a). Cartaz à Guiné-Bissau: registros de uma experiência em processo. 5. ed. São Paulo: Paz e Terra.

Freire, P. (2011b). Pedagogia do Oprimido. 50. ed. rev. e atual. Rio de Janeiro: Paz e Terra.

Freire, P. (2013). À sombra desta mangueira. Paulo Freire; Ana Maria de Araújo Freire. 11. ed. Rio de Janeiro: Paz e Terra.

Freire, P. (2014). Pedagogia dos sonhos possíveis. Organização Ana Maria Araújo Freire. $1^{a}$ ed. São Paulo: Paz e Terra. 
Freire, P. (2016). Pedagogia da solidariedade. Organização Ana Maria Araújo Freire, Walter Ferreira de Oliveira, $2^{a}$ ed. São Paulo: Paz e Terra.

Gatti, B. A., \& Barretto, E. S. (2009). Professores do Brasil: Impasses e desafios. Brasília: Unesco.

Gatti, B. A., Barretto, E. S., \& André, M. E. D. A. (2011). Políticas docentes no Brasil: Um estado da arte. Brasília: Unesco.

Ghedin, E., Oliveira, E. S., \& Almeida, W. A. (2015). Estágio com Pesquisa. São Paulo: Cortez.

Imbernón, F. (2006). Formação Docente e Profissional: formar-se para a mudança e a incerteza, 6 ed. São Paulo: Cortez Editora.

Kenski, V. M. (2007). Educação e tecnologias: o novo ritmo da informação. Campinas, São Paulo, Papirus.

Mantoan, M. T. E. (2005). Inclusão escolar: O que é? Por quê? Como fazer? São Paulo: Summus.

Mizukami, M. G. N. (2013). Escola e desenvolvimento profissional da docência. In: GATTI, B. A. (org.). Por uma política nacional de formação de professores. São Paulo: Ed. da Unesp.

Murphy, C. U., \& Lick, D. W. (2005). Whole faculty study groups: a powerful way to change schools and enhance learning. California: Corwin Press, Inc.

Pérez Gómez, Á. I. (2015). Educação na era digital: a escola educativa. Tradução: Marisa Guedes; revisão técnica: Bartira Costa Neves. Porto Alegre: Penso.

Pimenta, S. G. (2007). O estágio na formação de professores: Unidade teoria e prática? São Paulo: Cortez.

Skovsmose, O. (2007). Educação Crítica: incerteza, matemática, responsabilidade. Tradução Maria Aparecida Viggiani Bicudo. São Paulo: Cortez Editora.

Doutor em Educação Matemática - Curso de Matemática - Universidade Estadual de Goiás - UEG.7lucianolima@gmail.com 